\title{
Effects of cross-cultural experience on national images: a study of Scandinavian students in America ${ }^{1}$
}

\author{
HERBERT C. KELMAN \\ Department of Psychology and Center for Research on Conflict Resolution, \\ The University of Michigan \\ and
}

\section{LOTTE BAILYN}

Department of Social Relations, Harvard University

Experience in a foreign country exposes an individual to a variety of influences that may challenge his existing attitudes and values. $\mathrm{He}$ is confronted with new cultural patterns and solutions to life problems; he is expected to take on new roles and experiment with new forms of behavior; he interacts with different people and becomes involved in new groups; he is faced with challenges to some of his preconceptions; and he is able to observe himself in unfamiliar situations. These experiences may lead to varying degrees of attitude change, or to a confirmation of earlier attitudes and images, or, perhaps, to a defensive resistance to change. Changes that do occur may

\footnotetext{
${ }^{1}$ This paper is a product of a larger research program on social influence and behavior change, supported by grant M-2516 from the National Institute of Mental Health. An earlier version of the paper was read at the International Congress of Psychology in Bonn, August 4, 1960. We are grateful to Mary Lynne Bird and Marjorie Klein for their help in the analysis of the data reported here; and to Anita Mishler for her careful reading of the manuscript and her many helpful comments.
}

take on qualitatively different forms. For example, they may represent fairly temporary changes that disappear when the individual returns to his home setting, or fairly lasting changes that become independent of the immediate situation and integrated with the individual's value system. What are some of the patterns of change or of maintenance of attitudes and images that can be identified? What are the conditions under which each occurs and the psychological processes that give rise to it?

This is the general question we are exploring in the specific context of a study that involves a sample of Danes, Norwegians, and Swedes who spent a year in the United States. ${ }^{2}$ The study focuses on three aspects of self-imagery: one's nationality, one's profession, and the structure of one's personal relations. Information on these three elements of self-imagery was elicited from our respondents on three occasions: shortly after they arrived in the United States (in the Fall of 1958), shortly before their departure

${ }^{2} \mathrm{~A}$ previous report based on this study may be found in Bailyn and Kelman (1962). 
(in the Spring of 1959), and about a year after their return to their home countries (in the Summer of 1960).

Identical questions about nationality, profession, and personal relations were used on these three occasions to give us a basis for evaluating change. In addition, we elicited information (1) about the characteristics each individual brought to his American stay-his general values and personality dispositions, his background and home situation, and his motivations and expectations for the trip; (2) about his experiences during the stay and his reactions to these experiences-his ways of relating to new people and events, of involving himself in American life, of keeping himself open or closed to new discoveries; and, finally, (3) about his experiences and reactions upon returning to his home country. This information should help us to identify some of the determinants of different patterns of change and maintenance and the fate of these patterns when the individual returns to his home country.

Our sample is divided into three groups, each representing a different level of depth. The respondents in one group were seen once a month during their stay in America; those of a second group were interviewed intensively at the beginning and end of their

\section{TABLE 1}

Resfonses to the Criterual Item: "How GoOd ARE THE OpPoRTUNITIES THAT AN INDIvidual in Your Country Has for Leading the Particular Way of Life that appeals TO HIM?"

\begin{tabular}{|c|c|c|c|c|c|c|}
\hline \multirow[b]{2}{*}{ FALL } & \multicolumn{6}{|c|}{ SPRuNG } \\
\hline & $\begin{array}{l}\text { Very } \\
\text { good }\end{array}$ & $\begin{array}{l}\text { Fairly } \\
\text { good }\end{array}$ & $\begin{array}{c}\text { Aver- } \\
\text { age }\end{array}$ & $\begin{array}{l}\text { Fairly } \\
\text { limited }\end{array}$ & $\begin{array}{c}\text { Very } \\
\text { limited }\end{array}$ & $\begin{array}{l}\text { Total } \\
\text { FaLI }\end{array}$ \\
\hline Very good & 10 & 11 & 1 & & & 22 \\
\hline Fairly good & 9 & 31 & 10 & & & 50 \\
\hline Average & 2 & 9 & 4 & 2 & & 17 \\
\hline Fairly limited & & 1 & & & & 1 \\
\hline Very limited & & 1 & & & 1 & 2 \\
\hline Total SpRine & G 21 & 53 & 15 & 2 & 1 & 92 \\
\hline
\end{tabular}

stay; the third group filled in lengthy mail questionnaires on these same occasions. All three groups were questioned for a final time approximately one year after their return to their own countries.

In the present paper we shall deal only with a very limited aspect of our data: changes in national images manifested by our questionnaire respondents- 93 in allat the end of their year in America, i.e., changes from the 1958 to the 1959 questionnaires.

\section{Up-rating and Down-rating: Two Types of Change in National Image}

The starting point of this analysis is one questionnaire item, asked in the Fall of 1958 and again in the Spring of 1959: "How good are the opportunities that an individual in your country has for leading the particular way of life that appeals to him?" The 92 respondents who answered this item both times distribute their choices in the manner shown in Table 1.

In general, our sample feels pretty good about the opportunities in their own countries, both in the Fall and in the Spring. As a matter of fact, the marginal distribution on this question remains almost identical from the first to the second questionnaire. Nonetheless, patterns of change emerge. Only 46 respondents (50 per cent of the sample) maintain their opinions on this question (see the diagonal cells of the table). The other 50 per cent change: in the Spring, 24 (26 per cent) feel more pessimistic about the opportunities in their countries than they did in the Fall (upper right of the table); 22 (24 per cent) feel more optimistic about these opportunities (lower left of the table). It is these latter two groups that will concern us in this paper. We shall refer to the first group as down-raters and to the second as up-raters.

As is clear from Table 1 , down-raters 
TABLE 2

Marginal Distributions on the Criterial ITEM FOR DOWN-RATERS AND UP-RATERS

\begin{tabular}{lrrrrr}
\hline \hline $\begin{array}{l}\text { Percentage of each } \\
\text { group giving the } \\
\text { following responses: }\end{array}$ & \multicolumn{2}{c}{$\begin{array}{c}\text { DowN-RATERS } \\
(\mathrm{N}=24)\end{array}$} & \multicolumn{2}{c}{$\begin{array}{c}\text { UP-RATERs } \\
(\mathrm{N}=22)\end{array}$} \\
\cline { 2 - 3 } \cline { 5 - 6 } & Fall & Spring & & Fall & Spring \\
\hline Very good & $50 \%$ & - & & - & $50 \%$ \\
Fairly good & $42 \%$ & $46 \%$ & & $41 \%$ & $50 \%$ \\
Average or limited & $8 \%$ & $54 \%$ & & $59 \%$ & $0 \%$ \\
\hline
\end{tabular}

(upper right of table) were more enthusiastic about the opportunities in their own countries than up-raters (lower left of table) in the Fall, and less enthusiastic than upraters in the Spring. These differences are summarized in Table 2. Thus, these two groups differ both in initial position and in direction of change. The down-raters start out feeling good about the opportunities in their own countries, but at the end of the stay in America they see greater limitations. The up-raters, on the other hand, are initially somewhat discouraged about the opportunities in their own countries, but in the Spring they view these opportunities as rather good. No attempt has been made, in the present analysis, to separate out the effect of initial position from that of direction of change. Since, however, almost half of each group starts out in the middle category, it seems unlikely that initial position alone determines the relationship under discussion.

In order to characterize these two patterns more fully we will examine, in the next section, other aspects of the respondents' images of their countries which seem to be related to the direction of change on the criterial item.

\section{Changes in National Images Related to Down-rating and Up-rating}

Table 3 presents the changes of our criterial groups in other aspects of their national images. For the down-raters the following trends emerge: (a) As one might expect, they tend to change in the direction of seeing better opportunities in a big country rather than in a small country. Thus, presumably, their down-rating is partly due to the fact that they have become aware of some of the special opportunities in a big country and, by comparison, the limitations of their own countries.

(b) They tend to become somewhat less satisfied, in general, about living in their home countries. This change is largely accounted for, however, by shifts from a rating of "very satisfied" to a rating of "satis-

TABLE 3

Changes Manifested by Down-raters and Up-raters in Other Aspects of Their NaTIONAL IMAGES

\begin{tabular}{lcc}
\hline Net increase in the percent- & \\
age of each group (i.e., & Down- & UP- \\
spring percentage minus & RATEns & RATERs \\
fall percentage) giving & $(\mathrm{N}=24)$ & $(\mathrm{N}=22)$ \\
the following responses: & &
\end{tabular}

(1) The opportunities for leading the particular way of life a person wants to lead are better in a big country

(2) My country can contribute to the solution of international problems by joining with other countries to establish a force that would be independent of both East and West

(3) My country can contribute to the solution of international problems by serving as an objective observer and interpreter of world events, in a way not possible for the big powers

(4) The balance between government activity and private citizen activity is about right in my country

(5) I am very satisfied about living in my home country -11

(6) I am seriously considering moving to another country

* The percentages in this and subsequent tables are based on the number of people who actually answered the questions. "No answers" were assumed to be random and hence were excluded. 
fied." Thus, there appears to be no tendency to reject their own countries, but merely a reluctance to give them an unqualifiedly high rating. Presumably, these respondents have learned that, indeed, their countries have some limitations.

(c) They show an increased tendency to ascribe to their own countries the potential for contributing to the solution of international problems in the following two ways: 1) "by joining with other countries to establish a force that would be independent of both East and West" and 2) by acting as objective observers and interpreters. It is interesting that both of these points represent contributions that the country can make by virtue of its position outside of the big powers and without an assumption of independent power.

(d) They also tend to become more satisfied with the "relationship between the government and the citizen" in their countriesmore accepting of the amount of government control and government activity that characterize their socialist administrations.

This set of relationships seems to indicate a complex change in national image. The initial impression that down-rating merely reflects a more negative attitude toward the home country is not supported by the other changes that appear in Table 3. Rather, one might describe the change exhibited by the down-raters as one of refinement and differentiation of their national images. They have become more aware of the limitations of their countries but at the same time show a new understanding of the countries' advantages and potentialities. They now recognize a new role for their countries, appropriate to their size. This is particularly evident in their discovery of the unique contributions their countries can make to international relations. They seem to have accepted the fact that their countries are indeed small countries and that they cannot and need not compete with the big powers, but with this acceptance comes the new realization that they have a special contribution to make, different from that of the big powers. It is as if they had discovered the true identities of their countries and begun to understand their special character. On the domestic scene, they are more likely now to see the value of their governments' policy and to accept it-perhaps realizing its special relevance to a smaller country.

In contrast to the down-raters, up-raters tend to become more satisfied about living in their countries. In the Fall 23 per cent checked "very satisfied," while in the Spring 55 per cent selected this alternative. (For the down-raters the comparable figures are 37 per cent in the Fall and 26 per cent in the Spring.) Altogether 50 per cent of the up-raters changed in the direction of greater satisfaction. They also show another small but possibly important change: an increased tendency to indicate that they would seriously consider moving to another country.

This last finding, and the fact that uprating is not accompanied by any changes in conception of one's country and its contributions, seem to be out of keeping with the initial impression conveyed by the uprating pattern. They seem to suggest that up-rating, as opposed to down-rating, represents primarily a change in the affect attached to the national image-unaccompanied by any reorganization in its content or even, if the last item of Table 3 can be relied upon, any increased personal commitment to the home country. The up-rating pattern shows none of the differentiation that was evident in down-rating. Rather, it would seem that up-rating is a relatively global response of increased satisfaction with the home country, which is not based on any new insight into its special character.

Further evidence on the character of 
TABLE 4

Perceived Changes in Images of Their CounTruEs, AS REPORTED by the Respondents IN THE SPRING QUESTIONNAIRE

\begin{tabular}{lcc}
\hline $\begin{array}{l}\text { Percentage of each group } \\
\text { who report the following }\end{array}$ & Down- & UP- \\
kinds of changes: & RATERs & RATERs \\
\hline
\end{tabular}

(1) They have become more aware of the smallness of their own countries

(2) They have become more aware of the limitations and disadvantages of a small country

(3) They have come to appreciate their own countries when they observe the social pressure and the general tension and pace of life that characterize America

(4) They mention the social welfare in their countries as something they have learned to appreciate

(5) They mention the characteristics of the people in their countries and the relations among them as something they have learned to appreciate

(6) They mention nature, geography, or climate as aspects of their countries they have learned to appreciate

these two patterns may be obtained from two open-ended introspective questions asked in the Spring:

1) How has your picture of your own country changed?

2) Is there anything you have seen in America which has made you appreciate-perhaps for the first time-how good your own country really is?

The answers to the first of these questions confirm the fact that down-raters became more aware of the limitations of their own countries because of their small size. Table 4 shows that a sizeable proportion of downraters mention that they have become more aware of the smallness of their countries (item 1). Further, the down-raters who mention smallness tend to mention it in a negative way, i.e., to point to its limitations and disadvantages-while the up-raters mention it only in a neutral or positive context (item 2).

The complexity of the down-rater pattern becomes evident, however, when we look at the second introspective question. In answering this question, down-raters are more likely to stress the fact that they have come to appreciate their own countries when they observe the social pressure and the general tension and pace of life that characterize America (Table 4, item 3). Thus the downraters again manifest the two sides of their pattern. They seem to be saying that they have become more aware of the smallness of their own countries and of the disadvantages that this entails. At the same time, however, they have learned what price a country pays for its bigness and they have developed a greater appreciation for the way of life that only a small country can offer. Whether, on balance, they would choose the small country or the big country would no doubt depend on many circumstances, but their introspections reveal that they have become both more realistic about their own small countries and more appreciative of them.

The answers to these questions are consistent with the view of down-rating as a process of differentiation and reorganization of the national image. One down-rater, for instance, in answer to the question "How has your picture of your own country changed?" writes:

Not very much, but I see the limitations a small country has in professional opportunities and how dependent we are on people around us. Also I realize how poor the country is on natural resources and possibilities, and that after all Norway is an extremely small country. 
The other side of the pattern emerges from his answer to the second question:

I have learned more to appreciate the more quiet way of life, and the more relaxed view on life which you find in Norway. Also the opportunities for outdoor life, sporting, and hiking. The life in a society where you don't feel as much the social pressure from your environment seems more valuable to me now than it did before.

Another respondent writes, in answer to the first question:

From the beautiful, small, in all respects wonderful country I came from, there has now emerged a picture of provincialism, boredom, and apathy, but otherwise a nice peaceful place to live in.

To the second question he replies:

One thing which surprised me very much [about America] was the extreme contrasts of poverty and wealth. I especially got aware of it during my trip to Florida. Also this tremendous drive and strain imposed upon many students about getting ahead to get a big car has made me appreciate my country more.

Finally, a third down-rater answers the first question as follows:

Right now, as I am looking forward to go back, Denmark seems to be the most wonderful country in the world. But having lived in such a big country as America, I see the limitations of my country. Perhaps I see it more as the Americans seem to do, as Hans Christian Andersen's beautiful "fairy-tale country."

And to the second question he says:

I think it is true that it is not until you go away that you realize what your own country is like. I often have the feeling that America is too big for me, you can feel awfully lost here. I love Denmark because it is small. There is no real poverty. This I appreciate when I see the problems of the slums, the Negro problem, the problem of juvenile delinquency.

Returning to Table 4, we find that the up-raters, in contrast to the down-raters, were not likely to mention social patterns and institutions as things they have come to appreciate about their own countries (items 3,4 , and 5). Rather, they most frequently mentioned nature, geography, and climate (item 6). How can we interpret this emphasis?

An emphasis on nature certainly cannot be considered a trivial reaction. Scandinavians typically attach a great deal of importance to nature, and love of the nature of their countries tends to be a central aspect of their identification with the country. In this respect there is no difference between up-raters and down-raters. Thus, when respondents were asked in the Fall why they were glad to live in their own countries, 40 per cent of the up-raters and 39 per cent of the down-raters said "because of its nature." The up-raters' greater emphasis on nature in response to the question of what they have learned to appreciate about their own countries does not mean, then, that they value nature more highly than the down-raters. What it probably does mean is that, for many up-raters, this is all that comes to mind when this question is posed. They tend to have little in the way of new insights into the special characteristics of their countries and seem less able to produce some specific new learning. They are less likely, therefore, to speak of social patterns and institutions-responses that involve a more differentiated approach, a more analytic comparison between the two countries. Instead they speak of the relative virtue of the nature in their countries-a geographical given. By answering the question in this way they are, essentially, expressing their over-all feeling of appreciation of their countries and their attachment to them. They have come to realize more and more how much their countries mean to them, but they are unable to give any specific aspects of the country that they have learned to appreciate. 
The emphasis on nature thus seems consistent with the global pattern postulated for this group.

The following examples, especially when compared to the down-raters' statements given above, illustrate the undifferentiated character of up-rating. In response to the question "How has your picture of your own country changed?" one up-rater says:

Seems more glorious than ever-but this is just the little girl who is looking forward to see home again.

And to the question "Is there anything you have seen in America which has made you appreciate - perhaps for the first time- how good your own country really is?" she replies:

The climatel The cold New England winter; the hot New England summer.

Another up-rater says the following about the change in his picture of his own country:

It has not changed very much, just that I have learned how beautiful it really is, and how lucky I am.

As for things he has seen in America which have made him appreciate his own country more, he has the following to say:

The plains of Kansas. This is where I have stayed all the time, and I do not like to live where it is so flat. I also like the fact that girls are much more active in sports in Norway without having to be Physical Education majors.

A third up-rater indicates that his picture of his own country has not changed, and then answers the second question as follows:

I have learned to appreciate the nature of the country and the facilities we have to enjoy it still more than before.

Further confirmation of these characterizations of up-rating and down-rating comes from another analysis of these data. As part
TABLE 5

Ratings of "IDEALisM" (Concern with Value IMPLICATIONS AND SOCIO-CULTURAL Themes) RECEIVED BY DOWN-RATERS AND UP-RATERS

\begin{tabular}{lcc}
\hline \hline $\begin{array}{l}\text { Percentage of each group } \\
\text { who received the fol- }\end{array}$ & DowN- & UP- \\
lowing ratings: & RATERS & RATERs \\
\hline & $(\mathrm{N}=24)$ & $(\mathrm{N}=22)$
\end{tabular}

(1) High rating on idealism for description of changes in their picture of their own country

(2) High rating on idealism for new things they have come to appreciate in their own country

of his concern with a different problem, Shaffer (1961) coded the two introspective questions being discussed here on a dimension which he calls "idealism," and which he defines as follows:

The code dimension involves the extent to which the respondent sees his American experience as having implications for his own values (perhaps stimulating a reassessment of these values or a reconfirmation of them) and the extent to which he shows concern with fundamental socio-cultural themes within his own country.

Each answer was given a score between 0 (low on this dimension) and 4.

Table 5 shows that the down-raters score much higher on this dimension, indicating again the more differentiated nature of the change represented by down-rating as contrasted to the global character of up-rating.

It would appear, therefore, that for the down-raters the American experience leads to a more realistic and more negative appraisal of the opportunities in their own countries, given their small size. For many of these individuals, however, this seems to be part of a more general reappraisal of their countries which leads to an increased awareness of the special advantages of the country, of the personal meaning it has for them, and of their commitment to it. Their na- 
TABLE 6

Background Characterustics of DOWN-RATERS AND UP-RATERS

\begin{tabular}{lcc}
\hline $\begin{array}{l}\text { Percentage in each } \\
\text { category: }\end{array}$ & Down- & UP- \\
& RATERS & RATERS \\
& $(\mathrm{N}=24)$ & $(\mathrm{N}=22)$ \\
\hline
\end{tabular}

(1) Sex Male 55

Female 45

(2) Age at first interview

$\begin{array}{rrr}18-19 & 29 & 32 \\ 20-23 & 33 & 36 \\ 24-27 & 17 & 14 \\ 28-31 & 8 & 18 \\ 32 \text { or older } & 0\end{array}$

(3) Nationality

Danish _._. $25 \quad 27$

Norwegian _.. $42 \quad 41$

Swedish _.__ $33 \quad 32$

(4) Marital status

Single and unattached .... $54 \quad 59$

Single, but attached or engaged

\section{9}

Married

17

Spouse or fiance in America 12

27

(5) Previous foreign travel

A great deal 46

Some or none 54

tional images undergo a change that is characterized by differentiation.

The up-raters, on the other hand, show relatively little in the way of new insights and new discoveries about the value and meaning of life in their countries. Their responses seem to represent little more than an increase in positive feeling toward their own countries. The change in their national images is global and undifferentiated.

\section{Correlates of the Down-rater and Up-rater Patterns}

Before exploring some of the attitudes and reactions associated with the two patterns that have been identified, let us try to discover who the people are who exhibit these patterns. Do they differ in their backgrounds, their home situations, or their situations in America?

Table 6 presents the breakdown of each group by sex, age, nationality, marital status, and previous foreign travel. As can be seen, the two groups are very similar in all of these characteristics. With respect to age, it should be noted, however, that two of the down-raters are well into their thirties, while none of the up-raters is over 31 .

The groups do differ, however, with respect to some of their characteristics, as may be seen in Table 7. The table shows that down-raters are more likely to be in the social sciences and humanities, up-raters in science, mathematics, or business. With respect to other professional goals (engineering, law, medicine, teaching, etc.) the distributions are almost identical. Further, though the groups do not differ in terms of the level of professional attainment they had prior to their American trip, more up-raters than down-raters had their post-trip plans definitely arranged when they arrived in this country.

As far as their situations in the United States are concerned, two possibly relevant

TABLE 7

Struational Differences BetweEn DownRATERS AND UP-RATERS

\begin{tabular}{lcc}
\hline \hline $\begin{array}{l}\text { Percentage in each } \\
\text { category: }\end{array}$ & $\begin{array}{c}\text { DOWN- } \\
\text { RATERS }\end{array}$ & $\begin{array}{c}\text { UP- } \\
\text { RATERS }\end{array}$ \\
\hline
\end{tabular}

(1) Field

Social science and humanities _- $37 \quad 9$

Science and mathematics $4 \quad 14$

Business -.--.-- 4

(2) Post-trip plans

Definitely arranged on arrival 27

(3) Region of American stay

Midwest _........... $54 \quad 36$

West … $12 \quad 22$

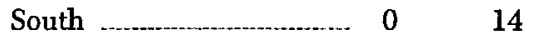

(4) Living arrangements in

America

Dormitory _. $32 \quad 55$

Fraternity or sorority ...... $41 \quad 30$ 
differences emerge. Almost a third of each group spent the year in New England or in the Middle Atlantic states. The distribution among the other regions, however, was dissimilar. Especially to be noted is the fact that not a single down-rater was in the South, whereas 14 per cent of the up-raters were. Second, the living arrangements of the two groups differed: more up-raters were in dormitories, more down-raters in fraternities or sororities. We shall refer to these differences as they become relevant, in the course of presenting the data that are the primary concern of this section: the relation of down-rating and up-rating to certain other attitudes.

Examination, in the preceding section, of the other changes in national images that seem to go with down-rating and up-rating on the criterial item has suggested two distinct patterns of change: an increased differentiation, characteristic of the downraters; and a global, undifferentiated change, characteristic of the up-raters. These two patterns are likely to reflect different reactions to the experience of being in a new environment. The differentiated change of the down-raters suggests a general attitude of openness to the new experiences. The global change of the up-raters, in contrast, suggests a strategy of resistance to the new experience: they seem to have related to the experience in such a way as to prevent it from affecting them and from producing new insights.

To investigate the hypothesis that downraters reacted to their experiences in America in an open way while up-raters manifested resistance, we can examine some additional data, taken from different parts of the two questionnaires. These data will allow us to see what other attitudes and reactions tend to be related to the downrating and up-rating patterns.
TABLE 8

AtTItUdes of Down-raters aNd Up-raters to THE AMERICAN Trup

\begin{tabular}{lcc}
\hline \hline $\begin{array}{l}\text { Percentage of various } \\
\text { responses to the } \\
\text { following questions: }\end{array}$ & DOWN- & UP- \\
RATERs & RATERs \\
$(\mathrm{N}=22)$
\end{tabular}

(1) How long have you wanted to take this trip? (Fall Quest.)

I have wanted to come to the U.S. for some time now and have tried hard to find a way

It was more or less accidental that the opportunity to come to the U.S. came up this year

(2) What is the relationship of your trip to America to your professional plans? (Fall Quest.)

It will probably make a difference to my career* My career will probably not be affected significantly by my trip to America

(3) Would it have been better for you to come at a different time? (Spring Quest.) It would have been better if I had come earlier, when I was younger and not as far advanced in my professional preparation It would have been better if I had come later, when I was older and further advanced in my professional preparation I came at the right time 75

* Included here are respondents who checked that "the trip to America was necessary to my career" and those who checked that "the trip was not necessary but it will probably make a difference to my career." Very few checked the former alternative.

** The two "old" down-raters are included in this group.

1. ATtITUDES OF THE TWO GROUPS TO THEIR AMERICAN TRIPS

Data on the attitudes of the down-raters and up-raters to their trips as a whole are summarized in Table 8 . All of the differences here are small, but the trends are interesting. From the Fall questionnaire we 
learn that the down-raters are more likely to have wanted to take this trip for some time. The up-raters are more likely to check that "it was more or less accidental that the opportunity to come to the United States came up this year." Also, the down-raters are more likely to state that the trip to America will affect their careers in some way. Both of these items imply that the down-raters were more highly motivated to make this trip. They sought it out more actively and expected it to make a difference, partly, no doubt, because their future situations at home were not yet definite. It seems reasonable to assume, therefore, that the down-raters came to their American experiences with a greater degree of openness, of readiness to learn and to compare.

On the Spring questionnaire, respondents were asked if it would have been better for them to have come at a different time. Most checked that they came at the right time, but, among those who did not, the up-raters were more likely to say that they should have come later, while the downraters were more likely to say that they should have come earlier. Perhaps the downraters would have preferred to come when they were younger and hence more open to their experiences, whereas the up-raters would have preferred to come when they were older and hence more set and less vulnerable to the impact of a new environment.

2. REACtions OF THE tWo GROUPS to AMERICA AND TO THEIR PERSONAL SITUATIONS IN AMERICA

Table 9 summarizes the relevant findings. When asked, in the Fall, if anything surprised them about the political, social, and economic views of Americans, up-raters were much more likely to give answers that were primarily negative. Not a single uprater gave a response that was primarily positive. Down-raters, on the other hand,
TABLE 9

REACTIONS OF DOWN-RATERS AND Up-raters to america and to Them Personal Struations IN AMmrica

\begin{tabular}{lcc}
\hline \hline $\begin{array}{l}\text { Percentage of various } \\
\text { responses to the } \\
\text { following questions: }\end{array}$ & $\begin{array}{c}\text { DOWN- } \\
\text { RATERS }\end{array}$ & $\begin{array}{c}\text { UP- } \\
\text { RATERs }\end{array}$ \\
\hline
\end{tabular}

(1) What, if anything, has surprised you about the political, social, and economic views of Americans? (Fall Quest.)*

(a) Emphasize negative reactions

Emphasize positive reactions

(b) Mention low standard of living and lack of opportunities

Mention high standard of living and good opportunities

(2) In general, would you say that your situation here is pretty much the way you had expected it to be before you came, or is it different from what you had expected? (Fall Quest.)

Better than I had

expected

Pretty much as I had expected

Disappointing

(3) Do you expect to come back to America again? (Spring Quest.)

Yes
No

\section{3}

$23 \quad 37$

(4) Assuming that you had an attractive professional opportunity here, would you choose to settle in America? (Spring Quest.)

I would definitely choose to settle here or I would consider it seriously

I would consider it but not very seriously or $\mathbf{I}$ would not consider it at all

* Open-ended question.

were almost equally prone to answer in a positive vein as in a negative vein. When we look specifically at statements about the 
standard of living and opportunities in America we find, again, that not a single uprater expresses himself positively, while 23 per cent of the down-raters do.

Different interpretations of these findings are possible. The differences may reflect differences in the experiences of the two groups and in what they were able to learn about the opportunities in America-and these experiences in turn may have a lot to do with their tendencies to up-rate or downrate their own countries respectively. To support this interpretation, one might point to the fact that 14 per cent of the up-raters were located in the South during their stay in America, while none of the down-raters was. Assuming that the relatively lower standard of living and the pattern of segregation that characterize the South may elicit negative reactions, would this not account in part for the difference between the two groups? When the responses of the up-raters who were located in the South are examined, however, it turns out that in fact only one of these respondents gives a negative reaction. Thus the interpretation of the difference in reaction in terms of a difference in the experiences to which the two groups were exposed is not supported, at least by the data on regional distribution. The differences seem to be more consistent with the interpretation that the up-raters are more resistant to the experiences they encounter, the down-raters more open. The tendency of the up-raters to emphasize negative features of America and to ignore positive features suggests a strategy of minimizing the impact of the new environment and not allowing the experience to affect them. For some of the up-raters, this resistance may constitute a defensive process, motivated by an ambivalence toward their own country and by an unverbalized attraction to America. Becoming too attached to America represents a threat since it may lead to estrangement from their own countries, dissatisfaction, conflict, guilt, and disappointment. The tendency to reject America and to dwell on its negative features (together with the increased feeling of satisfaction with their own countries) would help to protect these up-raters from such threatening possibilities. By contrast, the more balanced reaction of the down-raters may reflect a greater openness to the experience in general, a greater interest in understanding America, and a greater willingness to engage in self-examination and self-criticism.

This interpretation is reinforced by another item in the Fall questionnaire: when asked how their own situations in America compared with what they had expected, 29 per cent of the up-raters, as compared to 5 per cent of the down-raters, indicated some disappointment. Thus, their negative reactions extend not only to their feelings about America, but also to their feelings about their personal situations in America. This is a further indication that the negativeness of the up-raters reflects a general strategy of resistance, rather than an objective evaluation of what they have seen in America.

One more finding with regard to attitudes toward America should be mentioned here. As one would predict from their greater friendliness to America (which, by the way, does not mean an absence of criticism), down-raters are somewhat more likely to say in the Spring that they would expect to come back to America. But this difference disappears in response to the following question: "Assuming that you had an attractive professional opportunity here, would you choose to settle in America?" If anything, there is a small tendency for the up-raters to be more affirmative on this question. This suggests, again, that at least some of the up-raters may be attracted to America, but react negatively because this attraction is threatening 
TABLE 10

The Management of Cultural Differences BY DOWN-RATERS AND UP-RATERS

\begin{tabular}{lcc}
\hline \hline $\begin{array}{l}\text { Percentage of various } \\
\text { responses to the following } \\
\text { questions (all from the }\end{array}$ & DOWN- & UP- \\
Spring questionnaire): & RATERS & RATERs \\
\hline
\end{tabular}

(1) Did you ever find yourself comparing your own country to America?

Frequently

Occasionally or Hardly at all

(2) Do you find that you now compare yourself more with Americans than you did before?

Yes, very much

Yes, a little more No

(3) During your stay here, did you ever feel that Americans were expecting you to change your behavior to fit in with American patterns? Frequently to Occasionally

Hardly ever

(4) Did you ever try to persuade Americans to adopt any of your patterns of behavior?

Frequently to Occasionally

Hardly ever

or perhaps because no attractive professional opportunity in America has presented itself. The ambivalence implied by this finding is consistent with the observation (in Table 3) that the up-raters are slightly more likely to consider moving to another country.

\section{THE MANAGEMENT OF CULTURAL}

\section{DIFFERENCES BY THE TWO GROUPS}

Table 10 summarizes the findings on the way in which the down-raters and up-raters handled differences between America and their own countries. In the Spring questionnaire, down-raters were more likely to state that they had frequently found themselves comparing their own countries to America.
This greater tendency to compare is clearly consistent with the assumption that the down-raters are more open to their experiences and more willing to evaluate their implications. There is also a slight tendency for down-raters to say in the Spring that they now compare themselves more with Americans than they did before. While this question is not directly relevant to cultural differences, the pattern of responses suggests again that the down-raters are more likely to engage in a process of comparison.

Of great interest is the up-raters' tendency to feel that Americans expected them to change their behavior to fit in with American patterns. At the same time, they are somewhat more likely to state that they themselves tried to persuade Americans to adopt some of their patterns of behavior. Both of these tendencies are consistent with the interpretation that up-raters are more resistant to the impact of the new environment. A person who is concerned with being minimally affected by his experience is likely to be more sensitive to any implied pressures to change his behavior. Similarly, he may actively persuade others to change their behavior in order to counteract any effect they may have on him. It seems plausible to suggest that for at least some of the up-raters a defensive process was at work here. The American experience may have created or awakened doubts about their values and beliefs. One way of handling such doubts is to externalize them, to experience them as pressures deriving from the outside. Another way is to attempt to persuade others of one's position, thus denying any doubts and strengthening one's own conviction and, at the same time, soliciting social support for the threatened values.

We have some indication that the distinctive approaches of the two groups to their management of cultural differences may reflect general personality styles. Scores on 
a number of personality dimensions were available for our respondents. The only one that yielded a consistent difference between the two groups is perceptual sharpening. ${ }^{3}$ Down-raters are more likely to be perceptual sharpeners (33 per cent as compared to 18 per cent); up-raters are more often perceptual levelers ( 32 per cent as compared to 21 per cent). The down-raters' greater tendency to compare and greater openness to cultural differences are consistent with this sharpening style.

\section{THE ADJUSTMENT OF THE TWO GROUPS TO AMERICAN LIFE}

Table 11 summarizes the relevant data. In the Fall questionnaire, up-raters were more likely to express surprise about the ease, speed, and casualness with which they were able to adjust to American life. Downraters, on the other hand, were more likely to mention difficulties of adjustment, and to express surprise about the slowness of the process. Similarly, down-raters were somewhat more likely to admit to some degree of uneasiness about the remainder of their stay. Yet, on the same questionnaire, a slightly larger proportion of down-raters indicated that they had hardly been lonely at all since they had been in America. And, what is most interesting in this connection, downraters were more likely to state in the Spring questionnaire that they felt at home in America, while up-raters were more likely to state that they felt just like visitors.

It would seem that the up-raters adjusted more easily, but their adjustments were of a more superficial kind. Apparently, their standards were relatively low. They tried to

${ }^{3}$ For a description of the measure of this dimension, see (Shaffer, 1961). Perceptual sharpening refers to a tendency to observe and emphasize small differences between stimuli; perceptual leveling refers to a tendency to minimize and be unaware of such differences.
TABLE 11

The Adjustment of Down-raters and UP-RATERS TO AMERICAN LifE

\begin{tabular}{lcc}
\hline \hline $\begin{array}{l}\text { Percentage of various } \\
\text { responses to the } \\
\text { following questions: }\end{array}$ & $\begin{array}{c}\text { DowN- } \\
\text { RATERS }\end{array}$ & $\begin{array}{c}\text { UP- } \\
\text { RATERs }\end{array}$ \\
\hline
\end{tabular}

(1) Is there anything that has surprised you about your own reactions to your experience in America? (Fall Quest.)*

Mention the ease, speed, or casualness with which they adjusted

Mention the difficulty or slowness with which they adjusted

(2) In general, are you uneasy about the remainder of your stay here, or are you looking forward to it? (Fall Quest.)

Generally uneasy about it

Both, uneasy about some things and looking forward to others

Generally looking forward to it

(3) It is often not easy when one comes to a new place. Have you been at all lonely since you have been here? (Fall Quest.)

I have been quite lonely I was lonely at first, but am not so any more I have hardly been lonely at all

(4) Did you feel at home here or did you feel that you were just a visitor? (Spring Quest.)

I felt at home here or

I usually felt at home

I felt like a visitor here or I usually felt like a visitor

* Open-ended question.

make a quick adjustment to the situation, presumably without getting too involved with American culture and the people they met. As a result, they were less likely to experience difficulties and struggles, but they were also less likely to establish satisfying relationships and to come to feel at 
home. The down-raters, on the other hand, were more willing to open themselves up to experiences. They tried harder to become involved and made greater attempts to evaluate the situations and their reactions to them. As a result, their adjustments were slower and more difficult, and they were aware of more problems. But they found greater interpersonal satisfactions, and, in the long run, were more likely to feel at home. If this interpretation is correct, this more open and involved pattern led to a more thorough reevaluation of their own countries on the part of the down-raters and hence a more integrated change.

\section{THE PERSONAL SIGNIFICANCE OF THE}

AMERICAN EXPERIENCE FOR THE TWO GROUPS

We have seen that down-raters tend to be more open to their American experiences. They seem more eager to become involved and more willing to learn about American patterns-and, in the process, to develop their images of their own countries. There is also some evidence, summarized in Table 12 , that down-raters are more likely to treat their American experience as an opportunity to learn about themselves and to develop themselves, especially in their relations with other people.

When asked, in the Fall, to describe some of the important differences between their lives in America and in their home countries, down-raters are more likely to mention the differences in their living arrangements. That is, they mention that in America they live in dormitories or in fraternities or sororities while at home, in the majority of cases, they lived with their families. Since a larger percentage of up-raters than down-raters in fact lived on campus, the greater tendency of down-raters to stress this point is a rather suggestive finding. It can be interpreted to mean that down-raters are more oriented to-
TABLE 12

The Personal Significance of the American EXPERIENCE TO DOWN-RATERS AND UP-RATERS

\begin{tabular}{lcc}
\hline \hline $\begin{array}{l}\text { Percentage of various } \\
\text { responses to the }\end{array}$ & Down- & UP- \\
following questions: & RATERS & RATERs \\
\hline
\end{tabular}

(1) What are some of the important differences between your life here and in your home country? (Fall Quest.)*

Mention difference in living arrangement

Mention harder work

(2) Thinking back over your stay, what aspect of yourself would you say has been most affected by your experience here? In what way, if any, are you now a different person? (Spring Quest.)*

Mention that they have achieved a greater degree of selfhood

Mention that their relations with other people have improved

* Open-ended question.

ward the new interpersonal experiences, the new ways of relating to people, that the stay in America calls for. The fact that they now live in group settings or that they do not live with their parents is a feature of their lives in America that looms large in their eyes. By contrast, we find that 18 per cent of the up-raters mention that they have to work harder in America, while none of the down-raters gives this response. It may be that, for various situational reasons, the up-raters do have to work harder, in fact; or that they are simply more task-oriented; or that they escape into work, that they try to minimize personal involvement by keeping busy. In any event, the up-raters seem to be more oriented toward work than toward personal relations and self-development in general.

Further support for this interpretation comes from an item on the Spring questionnaire in which respondents were asked in 
what way, if any, they now see themselves "as a different person." Differences are small, but down-raters are somewhat more likely than up-raters to mention that they have achieved a greater degree of "selfhood"-i.e., that they have become more mature, more independent, more sure of themselves, more self-directed, more free to pursue their own goals, or that they have attained greater self-understanding. Downraters are also more likely to say that their relations with other people have improvedi.e., that they get along better with others, are more at ease in social situations, and are more interested in personal relationships. It would seem then, that-at least in their own judgments-the down-raters developed themselves and learned something new about themselves in the course of the American stay. For the up-raters the experience was less likely to have had this meaning.

\section{Conclusion}

The two groups that were compared in this paper were formed on the basis of their responses to a single item, asked on two occasions. The down-raters are those respondents who showed a decrease in their perceptions of opportunities in their countries, and the up-raters those who showed an increase. Examination of some of the other changes manifested by the two groups revealed two distinct patterns of change in national image: the down-raters tended to show an increased differentiation, while the up-raters tended to change in a global, undifferentiated way. These differences in patterns of change appear to be related to the way the person reacted to the experience of being in a new environment.

We have seen that the down-raters were more actively motivated for the American trip and came with a greater expectation that they would benefit from it. While they did not accept American patterns uncritically, they reacted more openly to what they saw. They were more likely to compare and explore differences and to evaluate them objectively. It took them longer to adjust to American life, but the adjustment was deeper: they tried to become involved with American culture and the people they met, and eventually they came to feel at home. They regarded the American experience as an opportunity for personal development, especially in their relations with others. This relatively open approach to their American experiences is congruent with the differentiated change that the image of their own countries underwent. They became aware of some of the limitations of their own countries, but at the same time they gained a new insight into the unique contributions that the country can make and the special virtues of its way of life.

The up-raters, on the other hand, were less motivated to come to America and expected less from their trips. They tended to react negatively to American patterns without opening themselves up to their implications. They were less likely to compare and to respond to the challenge of different patterns. They adjusted easily to American life, but the adjustment seemed to be relatively superficial and minimal: they avoided personal involvement and tended to feel like visitors. They were more oriented toward work and less oriented toward personal development and interpersonal relations. The global, undifferentiated change in the image of their own countries reflects this resistant approach to their American experiences. They became more satisfied with their own countries and the opportunities they offer, but they showed no new appreciation of the countries' potential contributions, institutions, or way of life.

There may be various reasons, of which only a few have been explored in this paper, 
why some people react more openly to their American experiences and others with more resistance: differences in reaction may be due to differences in personality style, or in general interests (as reflected, for example, in professional choice), or in the person's situation at home, or in his situation in America. Any one or combination of these factors may account for a person's approach to the new environment, and thus, in turn, for the nature of his change on the criterial item.

In speaking of the down-raters and the up-raters as two distinct groups, we do not wish to imply that our criterial item has identified two basic types of people. Rather, it has led us to identify two distinct processes to which down-rating and up-rating are related. It cannot be assumed that every person who showed a decrease in perceived opportunities at home (i.e., every downrater) is characterized by a differentiated change in national image resulting from an open approach to the American experience. Nor is every person who perceived greater opportunities at home (i.e., every up-rater) characterized by a global undifferentiated change, resulting from a resistant approach to the environment. These are two patterns that are systematically related to the direction of change on the criterial item, but they certainly do not characterize all of the down-raters and all of the up-raters, respectively.

On a more general level, the findings suggest some of the possible relationships between the nature of a person's experience in a foreign country and the nature of the effects that the trip engenders. The motivations and expectations that he brings to his foreign stay, the way he adjusts to life abroad, and the way he relates to the new patterns and the new people he meets, all have a bearing on the way his image of his own country changes.

\section{REFERENCES}

Bailyn, Lotte and Kelman, Herbert C. “The Effects of a Year's Experience in America on the Self-Image of Scandinavians: A Preliminary Analysis of Reactions to a New Environment," Journal of Social Issues, 18 (1962), No. 1, 30-40.

Shafren, John B. “The Sojourner's Orientation to a New Culture: A Study of Scandinavians in America." Unpublished doctoral dissertation, Harvard University, 1961. 